\title{
Is neuroendocrine cell differentiation detected using chromogranin A from patients with bone metastatic prostate cancer a prognostic factor for outcome?
}

\author{
YOSHIAKI YAMADA ${ }^{1}$, KOGENTA NAKAMURA ${ }^{1}$, SHIGEYUKI AOKI ${ }^{1}$, TOMOHIRO TAKI ${ }^{1}$, \\ HIROYUKI MATSUBARA ${ }^{1}$, SHOTOKU SAI ${ }^{1}$, KATSUYA NARUSE ${ }^{1}$, MOTOI TOBIUME ${ }^{1}$, REMI KATSUDA ${ }^{1}$, \\ KENJI ZENNAMI $^{1}$, NOBUAKI HONDA ${ }^{1}$, ATSUKO NAKAGAWA ${ }^{2}$ and HIROSHI IKEDA ${ }^{2}$ \\ Departments of ${ }^{1}$ Urology and ${ }^{2}$ Pathology, Aichi Medical University School of Medicine, \\ Nagakute-cho, Aichi 480-1195, Japan
}

Received November 17, 2005; Accepted January 16, 2006

\begin{abstract}
We evaluated the usefulness of overexpression of neuroendrocrine (NE) cell differentiation determined by immunohistochemical staining for chromogranin $\mathrm{A}(\mathrm{Cg} \mathrm{A})$ in diagnostic needle biopsy specimens of bone metastatic prostate cancers. A total of 50 patients diagnosed as having bone metastatic prostate cancer were studied. The period of observation was between 6.9 and 79.4 months (median 48.7 months). Cg A was detected by immunostaining using the labeled streptavidin biotin method. Cg A-positivity was defined as the presence of immunostained cells in $10 \%$ or more of the tumor. All statistical analyses were carried out using the Statistical Package for Social Sciences Software, version 10.0 for Windows. Eleven patients (22\%) were classified into the $\mathrm{Cg}$ A-positive group. There were no significant differences in clinical data between the Cg Apositive and $\mathrm{Cg}$ A-negative groups. The 5-year causespecific survival rate was $34.1 \%$ for the $\mathrm{Cg}$ A-positive group and $55.2 \%$ for the $\mathrm{Cg}$ A-negative group ( $\mathrm{p}=0.3763)$. The 3 year non-recurrence rate was $9.1 \%$ for the $\mathrm{Cg}$ A-positive group and $35.9 \%$ for the $\mathrm{Cg}$ A-negative group, and this difference was significant $(\mathrm{p}=0.0253)$. The 3 -year causespecific survival rates after recurrence were $38.4 \%$ and $42.3 \%$ respectively $(\mathrm{p}=0.8125)$. We consider that $\mathrm{NE}$ cell differentiation of the primary tumor in cases of bone metastatic prostate cancer is not a prognostic factor for outcome.
\end{abstract}

Correspondence to: Dr Yoshiaki Yamada, Department of Urology, Aichi Medical University School of Medicine, Nagakute-cho, Aichi 480-1195, Japan

E-mail: 101959@gk.amu.aichi-med-u.ac.jp

Key words: bone metastatic prostate cancer, chromogranin A, neuroendocrine differentiation, immunohistochemistry, outcome

\section{Introduction}

The involvement of neuroendocrine (NE) cell differentiation has been identified in recent years as a factor in the acquisition of resistance to endocrine therapy for prostate cancer (1). NE cells do not generally express androgen receptors, and do not undergo proliferation in response to androgen (2). They are accordingly believed to exhibit resistance to endocrine therapy with androgen ablation. With respect to the neuroendocrine substance secreted by NE cells, the existence of a mechanism that stimulates proliferation of neighboring tumor cells via a paracrine mechanism has been suggested (2). Autopsy investigations of patients who developed resistance to endocrine therapy and died of cancer revealed cases in which NE cells had proliferated and invaded at a high frequency (3). Chromogranin $\mathrm{A}(\mathrm{Cg} \mathrm{A})$ is most widly expressed in NE cell differentiation $(4,5)$. Many reports of previous research have stated that in immunohistochemical (IHC) investigations (4,6-8), serum concentration measurements of $\mathrm{Cg} \mathrm{A} \mathrm{(9-11)} \mathrm{are} \mathrm{significantly} \mathrm{correlated} \mathrm{with}$ outcome following endocrine therapy. All of these reports, however, included cases at a variety of clinical stages and undergoing different therapies. There have been no reports of studies on patients receiving the same therapy and whose outcome could be predicted by staining of diagnostic needle biopsy specimens sampled at the time of initial diagnosis of bone metastatic prostate cancer.

In this study, we examined diagnostic needle biopsy specimens from patients with bone metastatic prostate cancer for overexpression of NE cell differentiation by immunostaining for $\mathrm{Cg} \mathrm{A}$, and evaluated its usefulness as a prognostic factor for outcome.

\section{Subjects and methods}

Subjects. We studied 50 patients who had been examined at Aichi Medical University Hospital between January 1998 and December 2001, and who had been diagnosed with bone metastatic prostate cancer. The period of observation was between 6.9 and 79.4 months (median 48.7 months). The 
Table I. Patient characteristics stratified by chromogranin A immunohistochemical staining results.

\begin{tabular}{|c|c|c|c|}
\hline Characteristics & $\mathrm{Cg}$ A positive group & $\mathrm{Cg}$ A negative group & Total \\
\hline Patient & $11(22.0 \%)$ & $39(78.0 \%)$ & 50 \\
\hline Age (years) & $63-82$ & $61-91$ & $61-91$ \\
\hline Average age & $73.9 \pm 6.1$ & $73.3 \pm 7.8$ & $73.4 \pm 7.4$ \\
\hline Median age & 76 & 72 & 72 \\
\hline Serum PSA (ng/ml) & $50.0-3780.0$ & $34.0-10060.0$ & $34.0-10060.0$ \\
\hline Average PSA & $1016.0 \pm 1217.5$ & $1037.8 \pm 2035.1$ & $1033.0 \pm 1874.7$ \\
\hline Median PSA & 440 & 270 & 336.3 \\
\hline \multicolumn{4}{|l|}{ Gleason score } \\
\hline 7 & 0 & 4 & 4 \\
\hline 8 & 5 & 14 & 18 \\
\hline 9 & 4 & 20 & 25 \\
\hline 10 & 2 & 1 & 3 \\
\hline \multicolumn{4}{|l|}{ EOD grade } \\
\hline 1 & 2 & 12 & 14 \\
\hline 2 & 9 & 22 & 31 \\
\hline 3 & 0 & 3 & 3 \\
\hline 4 & 0 & 2 & 2 \\
\hline \multicolumn{4}{|l|}{ T stage } \\
\hline T1c & 1 & 1 & 2 \\
\hline $\mathrm{T} 2 \mathrm{a}$ & 3 & 3 & 6 \\
\hline $\mathrm{T} 2 \mathrm{~b}$ & 3 & 9 & 12 \\
\hline T3a & 1 & 0 & 1 \\
\hline T3b & 0 & 4 & 4 \\
\hline $\mathrm{T} 4$ & 3 & 21 & 24 \\
\hline Tx & 0 & 1 & 1 \\
\hline \multicolumn{4}{|l|}{$\mathrm{N}$ stage } \\
\hline N0 & 5 & 26 & 31 \\
\hline N1 & 6 & 12 & 18 \\
\hline $\mathrm{N} 2$ & 0 & 1 & 1 \\
\hline
\end{tabular}

Cg A, chromogranin A; PSA, prostate-specific antigen; EOD, extent of disease. No differences were statistically significant.

treatment method was maximal androgen blockade in all cases, with subjects receiving anti-androgen agents with LH-RH agonists in 47 patients and anti-androgen agents in addition to bilateral orchiectomy in three patients. In all cases, PSA levels fell below $4.0 \mathrm{ng} / \mathrm{ml}$ following MAB therapy. Table I shows the patient characteristics.

Methods. A prostate-specific antigen assay was conducted using a Tandem-R assay kit. (Hybritech, San Diego, CA, USA). Systematic sextant biopsy of prostate was carried out using an Aloka (Tokyo, Japan) SSB-650CL with an 18-gauge biopsy needle (Biopty, C. R. Bard, Covington, GA, USA) under transrectal ultrasound guidance. The clinical stage and extent of disease (EOD) grade were determined by computed tomography, magnetic resonance imaging, and bone scans. The difference between groups was tested for significance by using the Mann-Whitney U-test and the $\chi^{2}$ test, with a value of $\mathrm{p}<0.05$ considered significant. Survival and non-recurrence periods were calculated by using the Kaplan-Meier method, and the log rank test was used to determine the significance of difference. All statistical analyses were carried out using the Statistical Package for Social Sciences Software (SPSS, Chicago, IL, USA), version 10.0 for Windows. The day on which the clinical stage was determined was regarded as day 0 of observation. Recurrence was defined as the presence of biological failure and three consecutive rises in PSA levels, with the first rise counted as the date of recurrence. The final date of observation was December 31, 2004. The Gleason classification (12) was used for histopathological classification, and the Union Against Cancer Classification system (13) was used to evaluate the primary tumor and lymph node metastasis.

Immunohistochemical staining procedure and evaluation. Cg A was detected by immunostaining using the labeled streptavidin biotin method. Paraffin sections were prepared from the biopsy specimen: after deparaffinization and quenching the endogenous peroxidase activity with $0.3 \%$ hydrogen peroxide in methanol, the specimen was washed in phosphate-buffered 

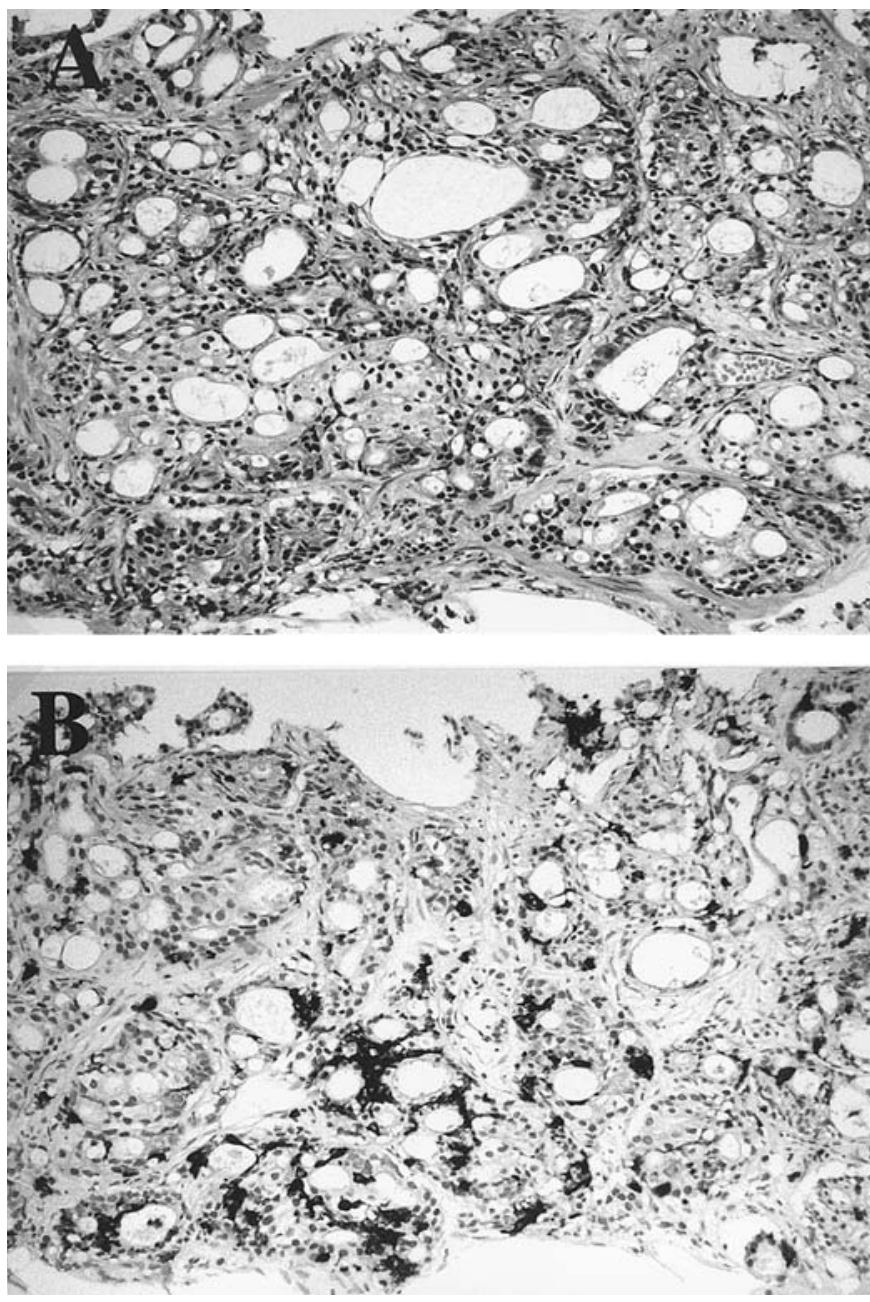

Figure 1. A, Hematoxylin and eosin staining of prostate specimen with Gleason score 4+4. B, Chromogranin A immunochemical stain showing granular staining in the cytoplasm.

saline (PBS, pH 7.4). Non-specific reactions were suppressed with 5\% normal goat serum, and rabbit anti-human $\mathrm{Cg} \mathrm{A}$ (Dako Cytomation, Glostrup, Denmark) diluted at 1:400 was applied as the primary antibody and allowed to react at $37^{\circ} \mathrm{C}$ for $30 \mathrm{~min}$. After washing in PBS, biotin-labeled mouse antirabbit IgG antibody was allowed to react at $37^{\circ} \mathrm{C}$ for $30 \mathrm{~min}$, after which the specimen was washed in PBS, reacted with horseradish peroxidase-labeled streptavidin at $37^{\circ} \mathrm{C}$ for $30 \mathrm{~min}$, and washed again. It was subsequently developed in diaminobenzidine and counterstained with hematoxylin for nuclear staining. The specimen were examined by two experienced pathologists and considered positive if the positively stained cells comprised $10 \%$ or more of the tumor area (Fig. 1).

\section{Results}

The Cg A-positive groups consisted of 11 patients (22\%) in whom $10 \%$ or more of the tumors showed positive staining. The Cg A-negative group consisted of 29 patients. Marginal cases included 8 patients with $1-5 \%$ staining and 2 with $5-9 \%$ staining. There was no statistically significant difference between the $\mathrm{Cg}$ A-positive group and $\mathrm{Cg}$ A-negative group with respect to age, serum PSA, Gleason score, EOD grade, T stage, and $\mathrm{N}$ stage (Table I).

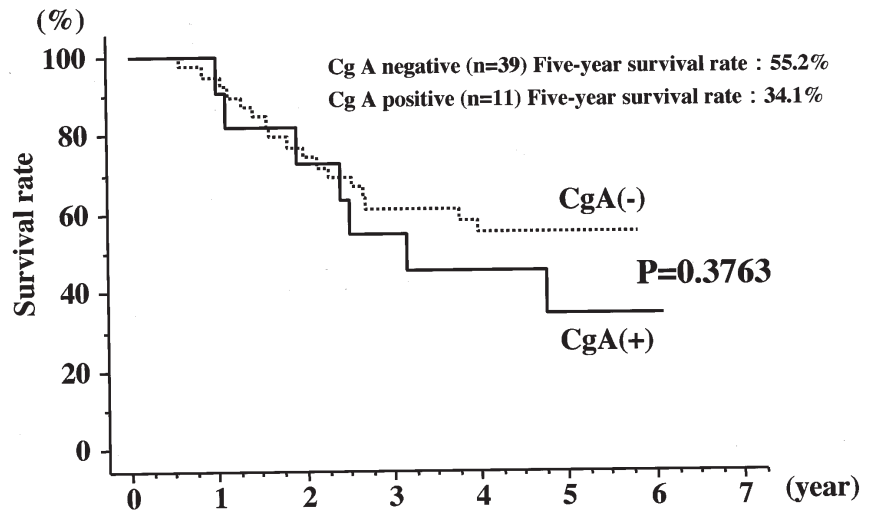

Figure 2. Cause-specific survival in Cg A-positive and Cg A-negative groups.

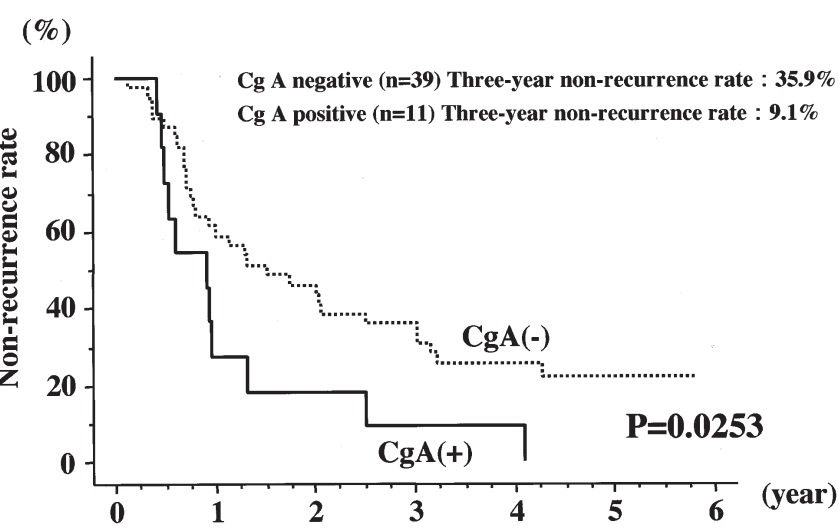

Figure 3. PSA-free recurrence in Cg A-positive and Cg A-negative groups.

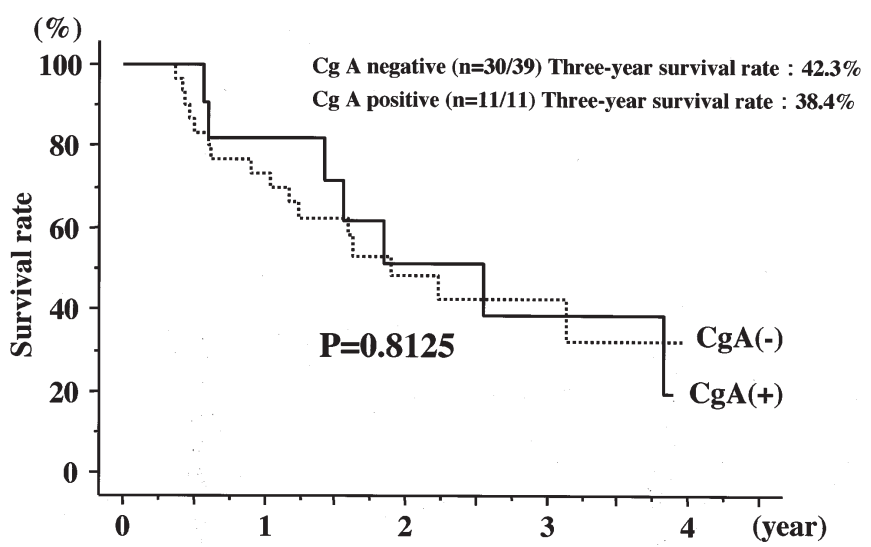

Figure 4. Cause-specific survival following recurrence in $\mathrm{Cg} \mathrm{A}$-positive and $\mathrm{Cg}$ A-negative groups.

The 5-year cause-specific survival rate was $34.1 \%$ for the $\mathrm{Cg}$ A-positive group and $55.2 \%$ for the $\mathrm{Cg}$ A-negative group ( $\mathrm{p}=0.3763$ ) (Fig. 2). The 3-year non-recurrence rate was $9.1 \%$ for the $\mathrm{Cg}$ A-positive group and $35.9 \%$ for the $\mathrm{Cg}$ A-negative group ( $\mathrm{p}=0.0253$ ). The cumulative $50 \%$ non-recurrence rate was reached within 0.603 year in the $\mathrm{Cg}$ A-positive group, but within 1.518 years in the $\mathrm{Cg}$ A-negative group (Fig. 3). Recurrence was observed in all 11 patients (100\%) in the Cg A-positive group and 30 out of 39 patients $(76.9 \%)$ in the 
Cg A-negative group. The 3-year cause-specific survival rates were $38.4 \%$ and $42.3 \%$ respectively ( $\mathrm{p}=0.8125)$ (Fig. 4).

\section{Discussion}

Androgen receptor abnormality is one mechanism whereby tumor recurrence occurs, however, there is also another mechanism independent of androgen receptors. The first mechanism may consist of 1) androgen receptor amplification (resulting in reaction to small amounts of androgen), 2) mutations in the androgen receptor gene (binding to and reacting with sub-stances other than androgen such as antiandrogen agents, estrogen, and steroids), 3) abnormalities of the co-activator that is a factor increasing the transcriptional activity of androgen receptors, or 4) abnormalities in the production of growth factors or cytokines, resulting in androgen receptor activation. Mechanisms proposed for the androgen-receptor independent mechanism are 1) abnormalities in the group of genes related to apoptosis, resulting in the avoidance of apoptosis, and 2) the appearance and proliferation of NE-differentiated cells. However, a combination of these abnormalities may be involved rather than abnormalities occurring singly (14).

NE cells are found in prostate tissue. They extend dendrites between their neighboring epithelial cells, and their cytoplasm includes granules of accumulated peptide hormones and prohormones. The function of NE cells within the prostate is unknown, but conjecturing from the functions of NE cells in the respiratory and digestive systems and in the pancreas leads to the consideration that they are indispensable to the growth and differentiation of the prostate, as well as to the homeostatic regulation of the endocrine process (1). $\mathrm{Cg} \mathrm{A}$ has been reported as being most universally expressed in prostate tissue during NE cell differentiation (15). Cg A in prostate cancer tissue has been suggested to correlate with prognosis (16).

Bostwick et al (16) used the number of positive cells as the criterion of positive staining. As Cg A-positive cells are observed in small numbers in normal prostate epithelium, however, in this study we defined $\mathrm{Cg}$ A-positive as the presence of positive cells in more than $10 \%$ of the surface area of the tumor (7). According to this classification, 11 out of $50(22 \%)$ patients were classified as $\mathrm{Cg}$-A positive, which is similar to the finding of NE cell differentiation in $25 \%$ of prostate cancers reported by Casella et al (15). Prueri et al (17) reported that the number of $\mathrm{Cg}$ A-positive cells was significantly greater in the group with Gleason scores of six or over. However, we found no significant differences in age, pre-biopsy serum PSA value, Gleason score, EOD grade, T stage or $\mathrm{N}$ stage between the $\mathrm{Cg}$ A-positive and $\mathrm{Cg}$ A-negative groups. Noordzji et al (18) and Isshiki et al (11) also found no significant differences or correlation in Gleason score or pathological stage with NE cell differentiation.

We used the Kaplan-Meier method to calculate and investigate the cumulative non-recurrence rate for the $\mathrm{Cg} \mathrm{A}$ positive and $\mathrm{Cg}$ A-negative groups, and found that the time to recurrence was significantly shorter for the $\mathrm{Cg}$ A-positive group ( $\mathrm{p}=0.0253$ ). It would normally be supposed that if the time to recurrence is short, the prognosis for life expectancy should be unfavorable. Our study, however, found no significant difference in either survival rate or survival following recurrence.

McWilliam et al (7) and Krijnen et al (8) reported the existence of NE cells as an independent prognostic factor for outcome. Their studies, however, included patients with different stages of the disease, unlike our study on patients with prostate cancer at a single stage. Aprikian et al (19) and Bostwick et al (16) studied advanced prostate cancer with lymph node metastasis, and reported no significant difference in survival rate for $\mathrm{NE}$ cell differentiation. In their in vivo research using PC-310 human prostate cancer xenograft cells, Jongsma et al (20) reported that androgen-dependent tumors decreased by apoptosis within a few days following castration, with $50 \%$ of the surviving cancer cells being positive for $\mathrm{Cg}$ A. They concluded that a proportion of tumor cells that had initially been androgen-dependent had differentiated into NE cells with no accompanying tumor proliferation following androgen ablation. Bonkhoff et al (2) also reported that NE cells have undergone their final differentiation and do not have the potential for proliferation. In addition, an in vitro study using prostate cancer cells reported that $\mathrm{Cg} \mathrm{A}$ inhibits the invasion and growth of prostate cancer cells (21). This shows that in patients with bone metastatic prostate cancer with a short time to recurrence, as the cancer cells are highly biological malignant potential, it is possible that $\mathrm{Cg} \mathrm{A}$ secretion increases as an attempt to suppress tumor proliferation through NE cell differentiation and to inhibit the growth of tumor cells. This may be the reason for the absence of a significant difference in survival rates, despite the significantly shorter period to recurrence.

In conclusion, NE cell differentiation determined by immunostaining for $\mathrm{Cg}$ A showed that the time to recurrence was significantly shorter for the $\mathrm{Cg}$ A-positive group than the Cg A-negative group $(\mathrm{p}<0.0253)$, but there were no significant differences in survival rate or survival following recurrence. We therefore consider that NE cell differentiation in the primary tumor in cases of bone metastatic prostate cancer is not a prognostic factor for outcome.

\section{Acknowledgements}

We are deeply indebted to the members of the Department of Urology and Department of Pathology of the Aichi Medical University School of Medicine for their support.

\section{References}

1. Abrahamsson PA: Neuroendocrine differentiation in prostate carcinoma. Prostate 39: 135-148, 1999.

2. Bonkhoff $\mathrm{H}$ : Neuroendocrine cells in benign and malignant prostate tissue: morphogenesis, proliferation, and androgen receptor status. Prostate 8 (Suppl.): 18-22, 1998.

3. Tanaka M, Suzuki Y, Takaoka K, et al: Progression of prostate cancer to neuroendocrine cell tumor. Int J Urol 8: 431-437, 2001.

4. Di Sant'Agnese PA: Neuroendocrine differentiation in carcinoma of the prostate. Diagnostic, prognostic, and therapeutic implications. Cancer 70 (Suppl.): 254-268, 1992.

5. Di Sant'Agnese PA and Cockett AT: The prostatic endocrineparacrine (neuroendocrine) regulatory system and neuroendocrine differentiation in prostatic carcinoma: a review and future directions in basic research. J Urol 152: 1927-1931, 1994.

6. Ather MH and Abbas F: Prognostic significance of neuroendocrine differentiation in prostate cancer. Eur Urol 38: 535-542, 2000 . 
7. McWilliam LJ, Manson C and George NJ: Neuroendocrine differentiation and prognosis in prostatic adenocarcinoma. $\mathrm{Br}$ J Urol 80: 287-290, 1997.

8. Krijnen JL, Bogdanowicz JF, Seldenrijk CA, Mulder PG and van der Kwast TH: The prognostic value of neuroendocrine differentiation in adenocarcinoma of the prostate in relation to progression of disease after endocrine therapy. J Urol 158: 171-174, 1997 .

9. Ischia R, Hobisch A, Bauer R, et al: Elevated levels of serum secretoneurin in patients with therapy resistant carcinoma of the prostate. J Urol 163: 1161-1165, 2000

10. Berruti A, Dogliotti L, Mosca A, et al: Circulating neuroendocrine markers in patients with prostate carcinoma. Cancer 88: 2590-2597, 2000.

11. Isshiki S, Akakura K, Komiya A, Suzuki H, Kamiya N and Ito H: Chromogranin A concentration as a serum marker to predict prognosis after endocrine therapy for prostate cancer. J Urol 167: 512-515, 2002.

12. Gleason DF: Histological grading of prostate cancer. A perspective. Hum Pathol 23: 273-279, 1992.

13. Sobin LH and Wittekind CH: TNM Classification of Malignant Tumors. 5th edition. Wiley-Liss Inc., 1997.

14. Debes JD and Tindall DJ: Mechanisms of androgen-refractory prostate cancer. N Eng J Med 351: 1488-1490, 2004.

15. Casella R, Bubendorf L, Sauter G, Moch H, Mihatsch MJ and Gasser TC: Focal neuroendocrine differentiation lacks prognostic significance in prostate core needle biopsies. J Urol 160: 406-410, 1998.
16. Bostwick DG, Qian J, Pacelli A, et al: Neuroendocrine expression in node positive prostate cancer: correlation with systemic progression and patient survival. J Urol 168: 1204-1211, 2002.

17. Pruneri G, Galli S, Rossi RS, et al: Chromogranin A and B and Secretogranin in prostatic adenocarcinomas: neuroendocrine expression in patients untreated and treated with androgen deprivation therapy. Prostate 34: 113-120, 1998.

18. Noordzji MA, van der Kwast TH, van Steenbrugge GJ, Hop WJ and Schroder FH: The prognostic influence of neuroendocrine cells in prostate cancer: results of a long-term follow-up study with patients treated by radical prostatectomy. Int J Cancer 62: 252-258, 1995.

19. Aprikian AG, Cordon-Cardo C, Fair WR, et al: Neuroendocrine differentiation in metastatic prostatic adenocarcinoma. J Urol 151: 914-919, 1994

20. Jongsma J, Oomen MH, Noordzij MA, et al: Androgen deprivation of the $\mathrm{PC}-310$ [correction of prohormone convertase-310] human prostate cancer model system induces neuroendocrine differentiation. Cancer Res 60: 741-748, 2000.

21. Nagakawa O, Fujiuchi Y, Fuse H and Saiki I: Differential effect of chromogranin A fragments on invasion and growth of prostate cancer cells in vitro. Urology 62: 553-558, 2003. 